\title{
The Association between Beliefs about Language Learning and Language Proficiency among Jordanian EFL Learners at Ajloun University College
}

\author{
Muntaha Ali Mohammad Al Momani \\ Department of English, Ajloun University College, Al Balqa Applied University, Jordan \\ Roba Mahmoud Ali Al-oglah \\ Applied Science Department, Ajloun University College, Al Balqa Applied University, Jordan
}

\begin{abstract}
This study aimed to examine the association between beliefs about language learning and language proficiency among Jordanian EFL learners at Ajloun University College. The data were gathered by two modified versions of data collection tools; a questionnaire examining the beliefs about language learning (developed by Horwitz (2001)) and (2) a language proficiency test (developed by Shoeib (2004)). The data collection tools were applied to randomly recruit 100 (Fifty male and Fifty female) participants from the English language department at Ajloun University College. The Statistical Package of Social Sciences (SPSS) was used to process the gathered data and responses. The Pearson Correlation Coefficient was used to examine the association between the participants' beliefs about language learning and their language proficiency. The results of the study indicated that there is a strong association between the students' (males and females) specific beliefs (in both males and females) on learning English Language and the level of their language proficiency. Therefore, the results also revealed that female participants were more proficient in using the language compared to their male counterparts. The study ended up with a conclusion stating that other factors, in addition to the students; beliefs about language learning, such as students' achievement, are affecting the level of language proficiency.
\end{abstract}

Index Terms - foreign language learning, beliefs, language proficiency, Ajloun College University

\section{INTRODUCTION}

Recently, English has become an integral part of the daily lives of the world's population in general (Nunan, 2001). English has now been used in almost every area for international communication. The number of individuals who speak English as their native language has crossed the limit of 300 million, while more than 400 million individuals have adopted English as a foreign language (Crystal, 1985). The importance of the English language is increasing worldwide and even little knowledge of English is considered necessary as it brings more opportunities for jobs and employment. One of the aspects of language learning processes, that is gaining huge consideration, are the beliefs related to them. The beliefs of learners about foreign language are an essential part of educational research for the reason that they are considered a key feature associated with learners' progress.

To explore the beliefs of English language learners is a significant matter to gain insight regarding their needs and for further development actions. When the learners enter their language classroom, their personality features such as beliefs, attitudes, behaviors, and language learning styles also become a part of the learning environment. These beliefs can be interpreted as psychologically developed concepts and approaches regarding this world, and include common assumptions that language-learning students embrace about themselves as learners with the factors that influence their process of learning. Several studies had confirmed the fact that the successful people in foreign language learning are directly influenced by what they think and perceive about the target language, its target speakers, the culture, and the learning setting (Hosseini \& Pourmandnia, 2013).

The emotions, attitude, and feelings of the learners affect their language learning process. The language learners may be influenced by the language learning processes, in both positive and negative ways. Therefore, the precise understanding of the expected effects while learning a foreign language can help in making the language learning or teaching process more practical and result-oriented. Another important feature that may hinder the language learning capability of a student is anxiety. It is one of the most distressing variables that refrain the students from successful learning of a foreign language. Anxiety can make the language learners nervous and afraid of the results of their poor aural/oral performance (Park \& Lee, 2003).

In a traditional classroom setting, the educational approach is usually teacher-centered that focuses on instructional activities and pattern drills. However, some students may not understand language learning in this way. For this reason, 
teachers are likely to meet students' expectations with the help of their teaching practices, or students may lose their confidence in language learning (Mason et al. 2013). This lost confidence would develop negative beliefs that will limit their ultimate achievement. For students, the procedure of exploring beliefs can allow them to understand themselves more in the learning process (Peacock, 1999). This process of exploring beliefs is the best way to guide students, both inside and outside the classroom setting, more effectively about the language learning process and facilitate learning with greater self-knowledge and autonomy (Yuen, 2002).

Many studies have been conducted on language learning beliefs and their impact on student learning (Horwitz, 1987; Bernat, 2004; Riley, 2009). The findings of such studies indicate that the linguistic information of students differs according to the attention they give to a task and the strategies they use to perform a task (Yuen, 2002). It had been observed that people who have positive attitudes of openness and curiosity, readiness to suspend disbelief or judgment regarding others' meanings, behaviors and beliefs are more successful in their oral proficiency of a foreign language (Gregersen and Horwitz, 2002).

It is quite clear for the researcher that the learner's beliefs have an important role in their experience, success, or failure as language learners. An understanding of learners' beliefs related to language learning processes can provide educators with a better understanding of their expectations, dedication levels, and satisfaction from foreign language learning classes. Based on the learner's beliefs, the teachers can decide on constructive teaching practices and methodologies. Besides, they can have a more flexible and rational approach in organizing learning opportunities for their lessons (Suwanarak, 2012).

\section{A. Statement of the Study Problem}

Beliefs hold a pivotal position in each discipline and play a vital role in dealing with human behavior and learning (Fishbein \& Ajzen, 1975). Beliefs about learning refer to those general myths, perceptions, and viewpoints that language-learning students bring along with them to their joined institute (Bernat et al., 2005).

Language learning refers to the process through which the language capability develops in a human. It is indeed true that learning a second language is not very easy, and is rather a very intensive and time-consuming activity (Oxford, 2003). This is why many techniques are utilized to get better in foreign language skills and one such technique is to enhance contact with the target language speakers. Although this is one of the ideal methods to improve language proficiencies in another language, its society, and culture, yet unfortunately, most of the second language learners remain unsuccessful in achieving their competence due to few chances of study abroad opportunities and get " impoverished or insufficient input in the target language" (Cummins, 1998, p. 3).

Individual beliefs and foreign language learning are closely related. Considering the classroom context, students' perceptions, beliefs, metacognitive processes to acquire knowledge and attitudes they bring along with them to the learning institution is recognized as an important factor contributing to their successful learning processes (Bernat $e t$ al .,2005). Beliefs of the students regarding their language learning may have a direct impact on their learning performance in their classrooms. For example, if a student believes that he does not have a good aptitude for foreign language learning, he would not put more effort to learn that language. This is how individual beliefs act as unlucky self-fulfilling predictions. The teachers must pay close attention to the students' beliefs to assess whether these beliefs have a positive or a negative influence on their learning capabilities (Bernat et al., 2005).

Learners of foreign language usually have certain beliefs, ideas, and opinions related to foreign language learning based upon their personal experiences and the exposure they get from learning environments including both formal and informal (Kayaoğlu, 2013).

Because the students have gained a lot of experiences throughout their educational career, chances are high that they can build their very own beliefs about the features and factors that affect the perceptual process that can make any learning process effective or ineffective (AAAS, 1990). This effective or ineffective learning can also be influenced by factors such as anxiety or motivation. Based on this assumption, the present study has been designed to focus on the given study problem and is an attempt to investigate the potential relationship between beliefs and their influence on the learning outcomes of foreign language learners. The study also aims to investigate EFL learner's beliefs and their connection with English language proficiency.

"Foreign Language learning depends largely upon the beliefs, attitudes, and behavior of the students who decide to get enrolled in this program. However, the process of learning a foreign language is also influenced by many factors such as anxiety or motivation that can limit or encourage the students' learning ability of a foreign language". (Nespor, 1987, P. 317)

\section{B. Objectives of the Study}

Foreign language learners have a variety of beliefs concerning language learning and when they go to a classroom, they carry these beliefs to their classes as well (Altan, 2006). These beliefs have a great influence on the learning behavior of the students and affect their language proficiency, efficiency, and effectiveness of its acquisition (Yuen, 2002). The beliefs of students about learning a foreign language have an evident relevance to the understanding of their expectations concerning commitment, satisfaction, and success in their language-learning classes (Horwitz, 2001). Considering the importance of the beliefs of students about the foreign language-learning process, the key objectives of conducting this study are as follows: 
- To identify the major beliefs held by foreign language learners regarding their foreign language learning.

- To evaluate the impacts (positive and negative) of students' beliefs on their foreign language proficiency.

- To assess the effectiveness of language learning regarding the students' beliefs.

\section{Significance of the Study}

In most developed countries, especially in Jordan, there are increasing attempts to develop the educational process, resolve its educational issues, and improve the educational process outputs. Thus, English language learning is a key concern for the educational authorities as it is a global language that participates efficiently in developing the educational system.

The present study holds a lot of significance and value for the daily teaching practices by providing insight about EFL learner's beliefs about language learning and their relationship to language proficiency at the higher education level. This study is important for the curriculum developers of foreign language courses who must keep in mind the assumption, beliefs, and expectations of foreign language learners while designing their courses. The targets, of course, must be planned in such a way that it meets the satisfaction criteria of the language learners, and reduces their anxiety levels, and encourages their motivation for foreign language learning.

This study can be significant because it could provide guidance for the teachers in getting knowledge about students' beliefs and enable them to devise learning strategies that can support and improve students' proficiency. Since students' beliefs have an impact on their use of effective strategies of language learning, therefore the knowledge gained from this study could assist in employing effective learning strategies.

\section{Limitations of the Study}

This study was confined to the investigation of the relationship between beliefs of EFL learners about language learning with their language proficiency. Also, participants of the study include the only second and third level of EFL students of the Faculty of Arts, Department of English at Ajloun University College in the academic year 2019/2020 . Narrowing the participants' category to the second and third-year students could be due to the ease of access of the researcher to this category of students.

\section{RESEARCH INSTRUMENTS AND PROCEDURES}

The present study is primary research based upon the analysis and the evaluation of the study questionnaire (adoption of the Horwitz Model of the Beliefs about language learning, 2001) and the Overall English Language proficiency test by Shoeib (2004) to assess whether the study sample possesses a satisfactory level of proficiency in English.

\section{A. Sample}

The participants of the study comprised of 50 male and 50 female students $(n=100)$ EFL students enrolled in the undergraduate English course as a part of their degree program. The age group of the participants varies between 20 to 24 years for both males and females.

\section{B. Instrument}

The researcher analyzed the validity of the research instrument using Cronbach Alpha calculating the correlation coefficient on each axis of the study. The questionnaire used in this study comprised 34 close-ended questions, which were analyzed through a five-point scale of "Strongly Agree", "Agree", "Neither agree nor disagree", "Disagree", and "Strongly disagree". The questionnaire for this research presented items on student's beliefs under three categories including; general beliefs about learning a foreign language in males and females, the specific beliefs about the proficiency of learning a foreign language in males and females, and the beliefs about applying strategies to improve English language learning in both male and female participants

In addition to the close-ended questionnaire, the researcher has also used the English language proficiency test to examine the overall mean scores on the grammar, vocabulary, and translation. The language proficiency test was conducted to analyze the average performance of the participants regarding the English language semantics. Language proficiency test administration aimed to investigate the correlation between students; beliefs and their strategy use.

\section{Beliefs about Language Learning Questionnaire (BALLI) Horwitz (2001)}

The questionnaire used in this study is an adoption of the Horwitz (2001) of Beliefs about Language Learning, commonly known as BALLI (Beliefs about Language Learning Inventory) that has been employed to investigate the beliefs of the English language learners. The Likert method being an authentic and reliable approach to present the summated rating was utilized as a scaling technique to evaluate the attitudes and responses of the participants.

The adoption of the Likert scale in terms of evaluating participants' responses towards a series of statements is targeted to analyze participants' attitudes as to what level do they agree or disagree with the items of the questionnaire.

The questionnaire has been determined on five points namely, "Strongly Agree", "Agree", "Neither agree nor disagree", "Disagree", "Strongly disagree". Once the scale is determined, the values are assigned to each of these points 
for scoring purposes. The point "Strongly Agree" has been scored 5, "Agree" is ranked as 4, "Neither agree nor disagree" is given a weightage of 3, "Disagree" is allocated a score of 2, and "Strongly disagree" has been assigned score 1 . To take out the average score on each item, the total scores are summed up or average. This is how, Likert scale is a multi item scale, following a summative model.

The researcher has ensured while selecting items of the questionnaire that they must be characteristic, which implies that they should either present a positive or negative opinion on each statement instead of selecting neutral items that do not work properly on a Likert scale as they fail to present a definite position regarding the attitude of the participant.

It is important to mention that while making this questionnaire, the researcher has made use of the previous qualitative and quantitative researches such as Kayaoğlu (2013) that helped to produce the questionnaire being used in the present study. The questions in this questionnaire have been framed to evaluate the following categories:

\section{The general beliefs about learning a foreign language in male and female participants:}

The items 1 to $5,10,11,22,24,25,26 \& 34$ (a total of 12 items) from the questionnaire have been formulated to analyze the general beliefs related to learning a foreign language for both male and female participants. These items reviewed the common beliefs of the participants as to how they view English language learning as an easy or a difficult practice for them.

2. The specific beliefs about the proficiency of learning a foreign language (in male and female participants):

The questionnaire items 5, 6, 15, 18, 23, 27, 28, 29, 30, 31, 32, and 33 ( a total of 12 items ) have been used to evaluate the personal beliefs of the English language learners towards their language proficiency and learning of a foreign language. An estimation of these items was assisting the researcher to explore the participants' personal perceptions/ beliefs regarding English language learning.

3. Beliefs about applying strategies to improve English language learning (in both male and female participants):

The questionnaire items 7,8,9,12,13,14,16,17,19,20 and 21( a total of 11 items ) have been used to review the appropriate language strategies that can be employed by the language learners to improve their English language learning. An evaluation of these items will show the different techniques /strategies that the language learners can use to improve their language proficiency (items had been adopted from Oxford's Strategy Inventory for Language Learning (SILL).

D. The Validity of the BALLI

TABLE (1)

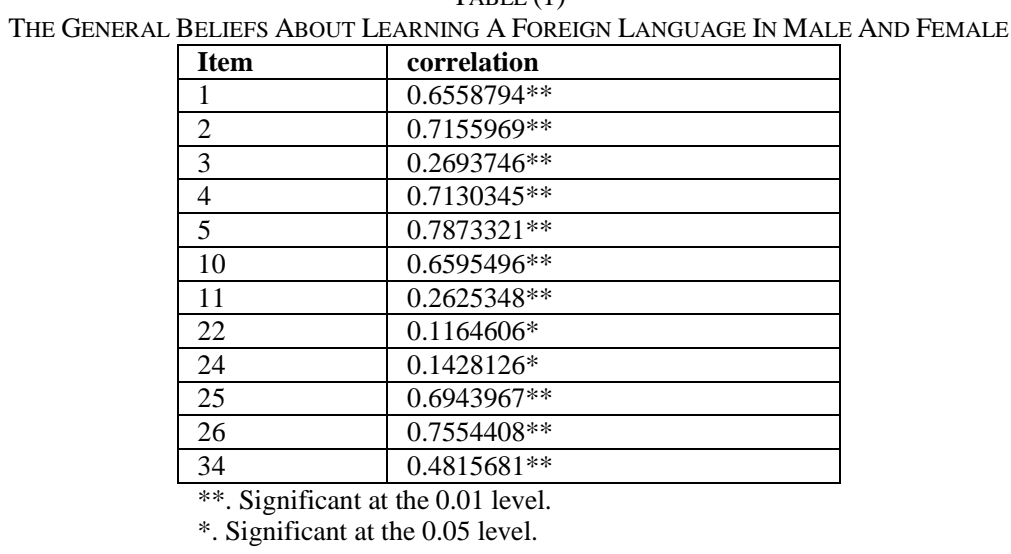

Table (1) shows the Pearson correlation factor values for the questionnaire items measuring the correlation of general beliefs about learning a foreign language

The measure of sincerity axis from the above item shows that there exists a high degree of correlation between all ferries except for the item number 22 and 24, and all items are significant at 0.01 level of significance. The difference in significance levels $(0.01$ or 0.05$)$ is related to the confidence interval utilized in the statistical analysis. 
TABLE (2)

The Specific Beliefs About The Proficiency Of Learning A Foreign Language In Male And Female Participant

\begin{tabular}{|l|l|}
\hline Item & correlation \\
\hline 6 & $0.585131 * *$ \\
\hline 15 & $0.2947114^{* *}$ \\
\hline 18 & $0.2480769^{* *}$ \\
\hline 27 & $0.2870307 * *$ \\
\hline 28 & $0.6315761 * *$ \\
\hline 29 & $0.6683504^{* *}$ \\
\hline 30 & $0.5957857 * *$ \\
\hline 31 & $0.7444554^{* *}$ \\
\hline 32 & $0.377438^{* *}$ \\
\hline 33 & $0.3851487^{* *}$ \\
\hline & $* *$ significant at the 0.01 level. \\
*significant at the 0.05 level.
\end{tabular}

Table (2) shows the Pearson correlation factor values for the questionnaire items measuring the correlation of specific beliefs about the proficiency of learning a foreign language among the study participants. The above table deduces the presence of a higher degree of correlation between the subcategory phrases (items number: 6, 28, 29, 30, 31) but shows a weaker correlation in the rest of the phrases with all items being significant at 0.01 level of significance.

\section{E. The Specific Beliefs about the Proficiency of Learning a Foreign Language in Male and Female}

Results are shown in table (3) show the Pearson correlation coefficient values among the study tool items related to the participants' beliefs about applying strategies to improve English language learning. There is a moderate to high correlation for items 9, 12, 14 16, and 19, and a weaker positive correlation for the rest of the items.

TABLE (3)

Beliefs About Applying Strategies To Improve English LANGUAGe LEARning (In Both Male ANd Female Participants

\begin{tabular}{|l|l|}
\hline Item & Correlation \\
\hline 7 & $0.4245818^{* *}$ \\
\hline 8 & $0.2457601^{* *}$ \\
\hline 9 & $0.7155726^{* *}$ \\
\hline 12 & $0.6489681^{* *}$ \\
\hline 13 & $0.268755^{* *}$ \\
\hline 14 & $0.5758473^{* *}$ \\
\hline 16 & $0.5387665^{* *}$ \\
\hline 17 & $0.30858^{* *}$ \\
\hline 19 & $0.6869261^{* *}$ \\
\hline 20 & $0.4717496^{* *}$ \\
\hline 21 & $0.2310281^{* *}$ \\
\hline & $* *$ significant at the 0.01 level. \\
*significant at the 0.05 level.
\end{tabular}

\section{F. Beliefs about Applying Strategies to Improve English Language Learning in Both Male and Female Participants}

It has been observed from the above table that there exists a high degree of correlation between the hub phrases (item number: $9,12,14,16 \& 19)$ but is weaker in the rest of the ferries but having all items being significant at 0.01 level of significance.

TABLE (4)

CORRELATIONS OF QUESTIONNAIRE AXES

\begin{tabular}{|l|l|}
\hline Category & Correlations \\
\hline The general beliefs & $0.8896279 * *$ \\
\hline The specific beliefs & $0.9041025^{* *}$ \\
\hline Beliefs about applying strategies & $0.9156425 * *$ \\
\hline$* *$ significant at the 0.01 level. & \\
*significant at the 0.05 level. &
\end{tabular}

It is evident from the above table that there exists a high degree of correlation between the axis of the questionnaire and the overall phrases.

G. The Correlation Coefficient between Axes 
TABLE (5)

THE CORRELATION COEFFICIENT BETWEEN AXES (MALE)

\begin{tabular}{|c|c|c|c|c|}
\hline & & $\begin{array}{l}\text { General } \\
\text { beliefs }\end{array}$ & \begin{tabular}{|l} 
Specific \\
beliefs
\end{tabular} & applying strategies \\
\hline \multirow[t]{3}{*}{ general Beliefs } & Pearson Correlation & 1 & .221 & $.313^{*}$ \\
\hline & Sig. (2-tailed) & & .123 & .027 \\
\hline & $\mathbf{N}$ & 50 & 50 & 50 \\
\hline \multirow[t]{3}{*}{ Specific. Beliefs } & Pearson Correlation & .221 & 1 & $.504^{* * *}$ \\
\hline & Sig. (2-tailed) & .123 & & .000 \\
\hline & $\mathbf{N}$ & 50 & 50 & 50 \\
\hline \multirow[t]{3}{*}{ Beliefs about applying. Strategies } & Pearson Correlation & $.313^{*}$ & $.504^{* *}$ & 1 \\
\hline & Sig. (2-tailed) & .027 & .000 & \\
\hline & $\mathbf{N}$ & 50 & 50 & 50 \\
\hline
\end{tabular}

*.significant at the 0.05 level.

**significant at the 0.01 level.

It was observed from the above table that there exists a direct relationship between all the axes of the questionnaire. The strongest relationship was observed between the specific beliefs on learning the English language and the beliefs on improving the strategies of learning, which was 0.504 at 0.01 level of significance.

TABLE (6)

THE CORRELATION COEFFICIENT BETWEen AXES (FEMALE)

\begin{tabular}{|ll|l|l|l|}
\hline & & $\begin{array}{l}\text { GENERAL.BELIE } \\
\text { FS }\end{array}$ & $\begin{array}{l}\text { SPECIFIC. } \\
\text { BELIEFS }\end{array}$ & APPLYING.STRATEGIES \\
\hline GENERAL. BELIEFS & Pearson Correlation & 1 & $.347^{*}$ & .265 \\
& Sig. (2-tailed) & .014 & .063 \\
& N & 50 & 50 & 50 \\
\hline SPECIFIC. BELIEFS & Pearson Correlation & $.347^{*}$ & 1 & $.665^{* *}$ \\
& Sig. (2-tailed) & .014 & .000 \\
& N & 50 & 50 & 50 \\
\hline APPLYING.STRATEGIES & Pearson Correlation & .265 & $.665^{* *}$ & 1 \\
& Sig. (2-tailed) & .063 & .000 & 50 \\
\hline
\end{tabular}

*.significant at the 0.05 level.

**significant at the 0.01 level.

It was observed from the above table that there exists a direct relationship between all the axes of the questionnaire. The strongest relation was observed between the specific beliefs on learning the English language and the beliefs on improving the strategies of learning, which was (0.665) at (0.01) level of significance

\section{H. Pilot Study of the BALLI / Questionnaire}

The beliefs about foreign language learning questionnaire have been administered to the same sample ( the overall English proficiency test sample) of the 10 students ( 5 males and 5 females) from the third and fourth-year students of the Department of English at the Faculty of Arts and Humanities at Ajloun University College. To determine the suitability and variety of statements to the students and their reliability.

\section{Reliability of the BALLI / Questionnaire}

TABLE (7)

RELIABILITY OF THE BALLI

\begin{tabular}{|l|l|l|}
\hline Category & No of Items & Reliability \\
\hline General beliefs & 13 & .729 \\
\hline Specific beliefs & 10 & .722 \\
\hline Applying strategies beliefs & 11 & .701 \\
\hline Total & 34 & .882 \\
\hline
\end{tabular}

The table above reveals that the reliability coefficient computed for the 12 items of the general beliefs about learning a foreign language in males and females was (.729). The 10 items of the Specific beliefs about the proficiency of learning a foreign language in male and female participants were (.722). The 11 items of the Beliefs about applying strategies to improve English language learning (in both male and female participants were (.701). The total of the 
whole questionnaire was (.882) which indicates that the questionnaire is of high reliability and is appropriate for administration.

\section{J. Scoring of BALLI Questionnaire}

Using a 1 to 5 Likert scale, the scores of the positive statements ranged from 5 to strong agreement to 1 for strong disagreement. All items of the Horwitz (2001) Model of Beliefs about Language Learning (BALLI) are positive statements.

\section{K. The Overall English Proficiency Test}

The proficiency test used in this research is a modified version of the proficiency test by Shoeib (2004) and it comprises four sections

- Cloze $(30 \%)$

- Vocabulary $(20 \%)$

- Grammar $(20 \%)$

- Translation $(30 \%)$

1. Cloze test construction: The close tests are used to measure high order skills, cohesion, and coherence. The present study has used a 184 words passage and has applied rational deletions to it to measure cohesion and coherence traits and the syntactic traits of the study participants. The close test involved three types of deletions: syntactic, cohesive, and coherence. The syntactic deletions depended only on clause level context, cohesive depended on inter-clausal or intersentential cohesive context and coherence depended on parallel patterns of coherence. A total of 15 items were observed in this test.

2. Multiple choice vocabularies: Four choices of different words were given to select the best one that could fill in the gap of the given statement.

3. Grammatical structure: Students are given twenty statements that they are required to complete, correct, supply, and converse as per given instructions.

4. Translation: The translation part has two passages. The first passage consists of 60 words that are to be translated from English into Arabic. The topic concerns unemployment. The main objective of adding this passage is to analyze the ability of the students to produce the grammatical and the lexical features of the source language as accurately as possible by locating their equivalents in the target language both in their meaning and the style.

The second passage requires to be translated from Arabic into English. This passage comprises of 41 words on the topic of education. The main purpose of this passage is to identify if the students can produce the grammatical and the lexical features of the target language as accurately as possible by locating their equivalents in the source language both in their meaning and the style

\section{Objectives of the Overall Proficiency Test}

The objectives of conducting the proficiency test are to see that the students can:

- Provide appropriate cohesion makers that are missing in the text

- Supply a syntactic trait deleted from the text

- Can complete suitable coherence markers which fit the spaces in the text

- Can recognize the appropriate word out of four distracters to suit the statement gap

- Can produce the accurate grammatical structure needed in the form of completion, supply, conversion, or correction

- Can give appropriate grammatical and lexical features of the source language by locating their equivalents in the target language with the same style and meaning

- Can provide appropriate grammatical and lexical features of the target language by locating their equivalents in the source language with the same style and meaning.

\section{The Validity of the Overall English Proficiency Test}

The test has been reviewed by the professors of Teaching English as a Foreign language that has read and judged it to suit the subjects and the purpose of this study.

TABLE (8)

TABLE $(8)$
\begin{tabular}{|l|l|} 
VALIDITy OF THE OVERALL ENGLiSH PROFICIENCY TEST \\
\hline Alpha Cronbach & No. of Items \\
\hline 0.966 & 4 \\
\hline
\end{tabular}

The result was 0.966 which considered a high and acceptable value for test validity. 
TABLE (9)

CORRElation OF EACH PART With TOTAL Marks Of THE TEST

\begin{tabular}{|l|l|}
\hline Close test & $.839^{* *}$ \\
\hline Vocabulary & $.946^{* *}$ \\
\hline Grammar & $.967^{* *}$ \\
\hline Total translation score & $.941^{* *}$ \\
\hline & $* *$ Significant at the 0.01 level. \\
\hline
\end{tabular}

It was observed from the above table there is a positive correlation between each section marks and the total mark and they are all statistically significant at the 0.01 levels.

\section{N. Pilot Administration of the Overall English Proficiency Test}

The test has been administered to a randomly selected sample composed of the 10 students from the study sample (BALLI sample) from the seventh and eighth levels students of the Department of English at the faculty of Arts at Ajloun University College. The purpose of conducting this test was to determine the suitability of the test to the students by analyzing their reactions and responses, calculating reliability, and the time needed to finish the test. The previous procedure had been performed to guarantee the validity, reliability, and consistency of the study instrument.

\section{O. Reliability of The Overall English Proficiency Test}

Due to the heterogeneity of the four parts of the test, a test-retest method was used to analyze the reliability of the test. The two administrations were separated for two weeks, to fulfill the test purposes and finding the differences between the scores of the two research groups. A reliability coefficient computed for the cloze questions (15) was (.84), for the grammar questions (20) using Alpha Cronbach the coefficient was (.97). The reliability coefficient for vocabulary questions (20) Alpha Cronbach the coefficient was (.90) that indicates high reliability.

TABLE (10)

RELIABILITY OF THE OVERALl ENGLISH PROFICIENCY TEST

\begin{tabular}{|l|l|}
\hline Alpha Cronbach & Items \\
\hline .934 & 4 \\
\hline
\end{tabular}

The above table shows that the result is 0.934 which considered a high and acceptable value for test reliability

TABLE (11)

Testing The Reliability Of The Overall English Proficiency Test

\begin{tabular}{|l|l|}
\hline Test & Correlation \\
\hline Cloze Test & $.839^{* *}$ \\
\hline Vocabulary & $.946^{* *}$ \\
\hline Grammar & $.967^{* *}$ \\
\hline Translate into Arabic & $.901^{* *}$ \\
\hline Translate into English & $.896^{* *}$ \\
\hline **significant at the 0.01 level. & \\
*significant at the 0.05 level. &
\end{tabular}

Table (11) shows the Pearson correlation factor values among the Overall English Proficiency Test components. Results indicate that there a strong positive correlation values for all of the test parts, which indicates that there is significant reliance on the Overall English Proficiency Test to answer the study questions or test the study hypotheses.

\section{P. Timing of the Test}

The researcher added the time which was taken by the first student to that taken by the last student to finish the test and divided it by two. So, the mean time calculated for the test was two hours and twenty minutes.

\section{ANALYSIS AND DiSCUSSION OF RESULTS}

The present study is primary research based upon analysis and the evaluation of the study questionnaire (adoption of the Horwitz Model of the Beliefs about language learning) and the Overall English Language proficiency test developed by Shoeib (2004).

\section{A. Testing of the Hypotheses}

It was noted that there is a direct relationship between the total scores of the proficiency test and the total male beliefs on learning a language with the value 0.264

The previous result is in line with the other previous studies such as Malcolm's (2004) study that showed that the EFL learners' beliefs on how important being good at English was for them represented how satisfied they were with different aspects of their English proficiency. Both the male and female respondents in this study believed that language 
learning is considered as dealing with an unfamiliar environment where the learner must make sense of through more exposure to the language and this more exposure would result in enhancing their language proficiency.

Another study by Al-Khairy (2013) conducted on the Saudi EFL/ESL learners indicated that the participants insisted on having 'more language courses' and some 'extra coaching facilities to help the weaker students to overcome their academic writing problems which indicated that a positive learner belief assists to enhance learners' proficiency.

A similar observation was seen in Suwanarak (2012) study where almost all of the EFL/ESL students with at least $91 \%$ of them believed that they needed regular practice to improve their language learning and communication skills. The study by Kayaoğlu (2013) also showed that there exists a possible correlation and a correlation between learner beliefs and their strategy use to improve their language proficiency. A study by Cheng (2001) also claimed that the influence of learners' belief in language learning is mediated by individuals' beliefs and goals, and thus supported the hypothesis of the present study. Cheng (2001) research also indicated a close relationship with second language anxiety and learners' self-perceived competence in learning the language.

\section{B. The First Hypothesis}

There are significant differences in 0.01 levels between male and female learners (BALLI) in favor of female learners.

TABLE (12)

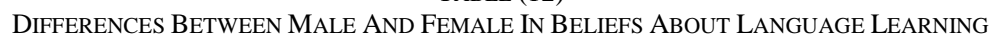

\begin{tabular}{|c|c|c|c|c|c|c|c|}
\hline & gender & $\mathbf{N}$ & Mean & Std. Deviation & $\begin{array}{ll}\text { Std. } & \text { Error } \\
\text { Mean } & \end{array}$ & & Sig. \\
\hline general.beliefs1 & $\begin{array}{l}\text { male } \\
\text { female }\end{array}$ & 50 & $\begin{array}{l}3.6450 \\
4.5550\end{array}$ & $\begin{array}{l}.33790 \\
.20105\end{array}$ & $\begin{array}{l}.04779 \\
.02843\end{array}$ & $\begin{array}{l}\text { Equal variances assumed } \\
\text { Equal variances not assumed }\end{array}$ & $.026^{* *}$ \\
\hline SPECIFIC.beliefs1 & $\begin{array}{l}\text { male } \\
\text { female }\end{array}$ & $\begin{array}{l}50 \\
50\end{array}$ & $\begin{array}{l}3.6980 \\
4.5700\end{array}$ & $\begin{array}{l}.42064 \\
.27866\end{array}$ & $\begin{array}{l}.05949 \\
.03941\end{array}$ & $\begin{array}{l}\text { Equal variances assumed } \\
\text { Equal variances not assumed }\end{array}$ & $246^{* *}$ \\
\hline $\begin{array}{ll}\text { BELIEFS } & \text { AB } \\
\text { APPLYING } & \\
\text { STRATEGIES } & \end{array}$ & $\begin{array}{l}\text { male } \\
\text { female }\end{array}$ & $\begin{array}{l}50 \\
50\end{array}$ & $\begin{array}{l}3.7636 \\
4.4655\end{array}$ & $\begin{array}{l}.40239 \\
.28786\end{array}$ & $\begin{array}{l}.05691 \\
.04071\end{array}$ & $\begin{array}{l}\text { Equal variances assumed } \\
\text { Equal variances not assumed }\end{array}$ & $.058^{*}$ \\
\hline
\end{tabular}

*.significant at the 0.05 level.

**significant at the 0.01 level.

Results are shown in table (12) reveal that, mean scores of the answers by female students for beliefs were higher compared to answers given by male ones so that females' answers tend to strongly agree to the male answers they tend to agree, which proves the hypothesis that there are differences in beliefs in favor of females, which means that females are likely than males to believe that students who learn a second language are more proficient in the English language.

It has been observed from the above table that the t-test value, which was calculated for all BALLI, axes (general beliefs, specific beliefs, and applying strategies) in case of assuming the variation is equal in more than (0.005) which verified the second hypothesis.

This hypothesis has been partially supported by a few of the previous studies. The study by The study by Malcolm (2004) that was conducted on the Arab medical school students also highlighted that most of the respondents (including both males and females) seemed generally satisfied with their ability in English, regarding the study purposes that may be attributed to the fact that a high number of respondents had attended and graduated from the English-medium schools.

A study by Adas and Bakir (2013) is in agreement with the current study hypothesis and indicates that constant exposure to the resources and materials helps both the male and female students to store more information that may result in improving their language learning performance. This achievement of the students can be attributed to their high learning beliefs and their belief to accept blended learning activities.

The findings of another study by Huwari and Al-Khasawneh (2013) were also in partial accordance with the study hypothesis and showed that the study respondents (Pre-Year students at Taibah University, Yanbu branch) had declared some main themes behind their weakness of English writing which was the grammatical weakness, their knowledge, and understanding and lesser chances of practice, etc. Therefore, the teachers as well as the curriculum should be focused on these themes to improve the language proficiency of language learners. Overall this hypothesis was partially approved if viewed per the above-mentioned studies as most studies supported the fact that there exist major differences between male scholars and female scholars in their beliefs regarding foreign language-learning. However, none of them indicated that these differences in beliefs favor female learners.

This hypothesis of the present study accords with the other studies that were conducted in the past years on this topic. The analysis of the study by Malcolm (2004) showed that the EFL learners' belief on how important being good at English was for them portrayed how satisfied they were with different aspects of their English proficiency. Both the male and female respondents in this study believed that language learning is considered as dealing with an unfamiliar environment where the learner must make sense of through more exposure to the language and this more exposure would result in enhancing their language proficiency. 
According to another study by Al-Khairy (2013), motivation is an important factor that is instrumental in successfully carrying out any activity and its significance is highlighted widely by a growing mass of motivational studies conducted in the field of second as well as foreign language learning contexts.

A similar observation was seen in Suwanarak (2012) study where almost all of the EFL/ESL students, with at least $91 \%$ of them believed that they needed regular practice to improve their language learning and communication skills.

The study by Kayaoğlu (2013) also showed that there exists a possible relationship and a correlation between learners' beliefs and their strategy use to improve their language proficiency. A study by Cheng (2001) also claimed that the influence of learners' belief in language learning is mediated by goals or beliefs of individuals, and thus supported the hypothesis of the present study. Cheng (2001) research also indicated a close relationship with second language anxiety and learners' self-perceived proficiency in learning a foreign language.

Generally, it is concluded from the previously presented results that there is a direct association between the students' specific beliefs (male and female) on learning English Language and the degree of their language proficiency. Therefore, this approves the first hypothesis of the current study.

\section{The Second Hypothesis}

There are significant differences of 0.01 levels between male and female EFL learners in their language proficiency in favor of female learners.

TABLE (13)

DifFerences In LANGuage Proficiency Between EFL Male AND FeMale LeARners

\begin{tabular}{|c|c|c|c|c|c|c|c|c|}
\hline gender & & $\begin{array}{l}\text { Cloze } \\
\text { test }\end{array}$ & Vocab & Grammar & $\begin{array}{l}\text { Trans. } \\
\text { A to E }\end{array}$ & $\begin{array}{l}\text { Trans. E to } \\
\text { A }\end{array}$ & Total translation score & $\begin{array}{l}\text { Total } \\
\text { marks ?/100 }\end{array}$ \\
\hline \multirow[t]{3}{*}{ male } & Mean & 10.82 & 15.60 & 10.10 & 4.54 & 7.56 & 12.06 & 64.78 \\
\hline & $\mathbf{N}$ & 50 & 50 & 50 & 50 & 50 & 50 & 50 \\
\hline & Std. Deviation & 3.816 & 3.464 & 6.052 & 2.908 & 2.417 & 5.048 & 23.292 \\
\hline \multirow[t]{3}{*}{ female } & Mean & 11.30 & 15.50 & 10.64 & 5.24 & 7.64 & 12.88 & 67.36 \\
\hline & $\mathbf{N}$ & 50 & 50 & 50 & 50 & 50 & 50 & 50 \\
\hline & Std. Deviation & 3.370 & 3.352 & 5.506 & 2.677 & 2.117 & 4.702 & 20.763 \\
\hline \multirow[t]{3}{*}{ Total } & Mean & 11.06 & 15.55 & 10.37 & 4.89 & 7.60 & 12.47 & 66.07 \\
\hline & $\mathbf{N}$ & 100 & 100 & 100 & 100 & 100 & 100 & 100 \\
\hline & Std. Deviation & 3.590 & 3.392 & 5.762 & 2.803 & 2.261 & 4.871 & 21.990 \\
\hline
\end{tabular}

**Significant at the 0.01 level.

*Significant at the 0.05 level.

It was observed from the above table (13) that the arithmetic average of the test amongst the male participants was $(64.78 \%)$, and was $(67.78 \%)$ amongst the female participants with a general average for both falling at $(66.07 \%)$

The efficient use of language through sections set as shown in the above table and through the average total scores for males and females is clear to us that the average score obtained by the males is (64.7) and females were average scores in all the test sections are (67.3) This means that females have efficiency using the language of a much higher degree than the male which validates the hypothesis.

The study by Javid \& Umer (2014) which mentioned that the lesser support from the family as well as a society regarding providing female Arab EFL learners with adequate opportunities to practice and repeat the target language outside their classroom, creates a major barrier to their effective learning.

Moreover, the study by Abbasian, Khajavi\& Mardani (2012)revealed that males use more effective learning strategies than female participants.

The research by Adas \& Bakir (2013) also goes in line with the above hypothesis where it was highlighted that the belief in correcting their mistakes themselves and improving their learning unconsciously motivated both male and female participants to read more and write more and this exposure helped students to give more attention to the proper use of the language.

Kayaoğlu (2013) in his study also highlighted that epistemological beliefs are a major part of the underlying mechanism of language behavior and they exercise a persistent influence on language learners. Therefore, overall, in this study, the average scores of both genders remained quite close in all the tests, but there existed significant differences between the averages of the EFL/ESL learner beliefs in favor of the female experimental group.

\section{DISCUSSION}

The analysis of the present study has highlighted the following:

\section{A. An Evaluation of General and Specific Beliefs}

The analysis of the results of the study was divided into three categories; general beliefs, specific beliefs, and beliefs about applying strategies to improve English. Language Proficiency Test results were used to investigate EFL learner's 
beliefs and their connection with English language proficiency. The data was analyzed under each category where the results portrayed female respondents as having a strong agreement with each item of all categories more than male respondents. The strong agreement among female students to the statement that 'It is easier for children than adults to learn a foreign language' mentioned in the category of general beliefs was found significant among both male and female respondents with the relationship being significant at (0.05) level of significance showing more female participants supported this statement than males.

This finding was in line with the finding of the Daif's study (2012). He also reported that most of the respondents in his study had favored the common belief that children are indeed better language learners as compared to adults. The analysis of another statement from the specific beliefs about the attitude regarding foreign language learning showed a (0.29) level of significance indicating that most male and female participants had accepted this statement. These results are also in compliance with what has been reported by Ayman Sabry(2012) that $79 \%$ of the participants in his study believed that they possess a special aptitude for foreign language learning. Evidence for this agreement is that with the spread of globalization, the importance of communication in the foreign language has increased even for Saudi students. Therefore, they are becoming more interested in learning a foreign language particularly English.

Further analysis of the statements under specific beliefs highlighted that regarding the effects of intelligence on language learning, most participants in both males and females had believed that people who speak more than one language are intelligent as the level of significance was (0.38). This finding is per Daif's study(2012) who stated that $50 \%$ of the respondents from his study either strongly agreed or agreed to the claim that 'people who speak more than one language are very intelligent'. According to the same study, 54\% of the respondents agreed that it is easier for someone who already speaks a foreign language to learn another one 7 which was also in compliance with the findings of the present study where both male and female participants agreed or strongly agreed to the statement with (0.37) level of significance. Overall, the results from the present study revealed that the participants had positive evaluations of their language learning abilities, and they seemed keen to learn a foreign language.

Regarding specific beliefs, there were observed significant differences amongst both male and female participants about the statement regarding a person who is good at other subjects like Math and science may not necessarily be a good foreign language learner. The level of significance observed was (0.66) and female respondents strongly favored the statement as compared to males.

\section{B. The Analysis of the Beliefs on the Use of Language-learning Strategies}

An evaluation of the study findings represented that most of the language learners understood the importance of applying different strategies to improve their language learning. It was noted that both male and female participants had agreed that 'it is important to speak a foreign language with an excellent accent' with (0.42) level of significance. This depicts, that participants from both the genders had realized the importance of having a good accent in language learning which may motivate them to apply techniques for improving their language.

The responses to the item regarding 'if I heard someone speaking the language- I am trying to learn I would go up to him to practice speaking the language' shows the application of social strategies by the participants. Varied opinions were observed for agreement in this category both in male and female participants with the (0.64) level of significance. This indicates that a high proportion of EFL learners in Ajloun University College are hesitant to go and speak to the native speakers to learn the English language.

The results also state that the successful learners are more aware of the usefulness of the social strategy (strategies that are applied to improve language learning by enhancing social interaction) use and try to intentionally seek the opportunities for interacting with other language users as a measure to improve their proficiency of the target language as compared to their unsuccessful peers. These results are in accord with the study of Geramia \& Baighlou (2011) which indicates the application of social strategy by successful and unsuccessful students with mean scores of successful students being higher than the mean scores of unsuccessful students.

The present study also analyzed the use of meta-cognitive strategies (strategies that involve the use of processes designed for students to improve their language learning) in both male and female participants. It was found out that the study participants apply more of meta-cognitive strategies to manage their learning than any other strategies as such for their language improvement.

The items regarding 'repeat and practice', 'Learning of grammar rules' and 'the importance to practice in a language laboratory' clearly highlight the use of metacognitive strategies in language improvement with the level of significance being reported as $(0.30),(0.47)$ and $(0.23)$ respectively. Participants from both genders show strong agreement to all the items concerning the use of these strategies. These findings are according to what has been mentioned by Geramia \& Baighlou (2011) as they claim that their study proves that meta-cognitive strategies have been used maximally by high achieving language learners. The present study depicts that there have been significant differences in the use of metacognitive strategies amongst male and female learners. A reason was given by Geramia \& Baighlou, (2011) for these differences is that the application of meta-cognitive strategies demands a higher proficiency of the target language. Geramia \& Baighlou (2011) also reported that successful students apply metacognitive strategies and are considered high meta-cognitive strategy users, but the unsuccessful students are the medium meta-cognitive strategy users.

C. A review of the Language Proficiency Test Findings 
The findings from the current study highlight that both the male and female participants showed an average performance in the test being conducted to evaluate the English language use of the participants on the close test, vocabulary, grammar, and translation. However, in overall scores, female participants showed better performance as compared to male participants except for the vocabulary scores. This can be attributed to the fact that owing to the lesser opportunities available to communicate in English with people outside their community, Saudi female students have limited vocabulary in comparison to their male peers. Male students have better vocabulary because they have more chances to interact with people speaking English outside the university than their female peers.

It was also noted that the female participants on an average performed higher than the male ones on the scale of the close test, grammar, and translation. This depicts that the Saudi female students are better and keen learners of the English language as compared to their male counterparts and they are better in most aspects of written language expressions than males. However, the overall performance of both the genders was observed to be just average where the total average score of male participants in the language proficiency test was (64.78) and the average score of the female participants was (67.36). The result implies that the overall performance of Saudi students in the language proficiency assessment is just an average. From my perspective, that through my experience in teaching English in high schools, Saudi students are overall not very keen learners of English as a foreign language and they find it a language difficult to learn. This has also been supported by the results of the language beliefs in the current study where both male and female participants reported learning English as 'Difficult' and 'medium-difficult.' But besides these results, it is noteworthy that most of the participants from both genders are aware of the importance of having a special ability that helps them learn a foreign language. These results are consistent with the Kayaoğlu (2013) study who mentioned that in his study both poor and good learners had strongly believed in the importance of having a special ability for language learning.

\section{Analysis of Gender Effect on Learners' Beliefs and the Language Proficiency Test}

A detailed evaluation of the current study showed that most participants were affirmative that females are better than men at learning foreign languages as the level of significance was (0.01) showing that both male and female participants had agreed to this statement. This is in relevance with the findings of Al-Kalani (2013) study who also mentioned in his study that most respondents held positive opinions regarding the importance of gender in language learning and believed that women are better than men at learning foreign languages.

Another aim of the study was to evaluate gender differences in the language proficiency of the male and female participants. The study analyzed whether there are any significant gender differences in learners' beliefs about English with relation to the BALLI items as well as on the language proficiency test scale. The hypothesis in the study also claimed that there exist significant differences in gender on Saudi university students' beliefs regarding English language learning. The results of the responses showed significant differences in most items of the study in both male and female participants where female participants reported having a higher degree of agreement on all items.

The results from the language proficiency test also reported that the performance of female participants in the cloze test, Grammar, and translation remained higher than male participants and females only scored lesser than the male ones on the vocabulary scale. This can be attributed to the fact that Saudi female students have less exposure to vocabulary usage than their male counterparts due to their rare interaction with native speakers outside the university so Saudi male students may have a better vocabulary than Saudi female students.

\section{CONCLUSION AND RECOMMENDATIONS}

The findings of this qualitative-quantitative study support the assumption that Saudi male students have a difference in their opinions regarding language learning beliefs and attitudes as well as their language proficiency in comparison to the female students as the female students outshine male students with their better language skills and aptitude for language learning.

Furthermore, the beliefs of females regarding English language learning and applying strategies to improve the language are far stronger when compared to their male counterparts.

\section{REFERENCES}

[1] Abbasian, R., Khajavi, Y., \& Mardani, A. (2012). Language learning strategies of Iranian EFL learners: Are gender and educational level important. Academic Research International, 3(2), 350-356.

[2] Adas, D., \& Bakir, A. (2013). Writing difficulties and new solutions: Blended learning as an approach to improve writing abilities. International Journal of Humanities and Social Science, 3(9), 254-266.

[3] Al-Khairy, M. A. (2013). Saudi English-Major Undergraduates' Academic Writing Problems: A Taif University Perspective. English Language Teaching, 6(6), 1.-12.

[4] Altan, M. X. (2006). Beliefs about language learning of foreign language-major university students. Australian Journal of Teacher Education, 31(2), 545-52.

[5] American Association for the Advancement of Science. (1990). Project 2061: Science for All Americans. Washington, DC: American Association for the Advancement of Science.

[6] Bernat, E. (2004). Investigating Vietnamese ESL learners' beliefs about language learning. English Australia Journal, 21(2), 40.-46. 
[7] Bernat, E., \& Gvozdenko, I. (2005). Beliefs about language learning: Current Knowledge, Pedagogical Implications, and New Research Directions. Tesl-ej, 9(1), n1.

[8] Cheng, Y. S. (2001). Learners' Beliefs and Second Language Anxiety. Concentric: Studies in Linguistics, 27(2), 75-90.

[9] Crystal, D. (1985). How many millions? The statistics of English today. English Today, 1(01), 7-9.

[10] Cummins, J. (1998). E-lective language learning: Design of a computer-assisted text-based ESL/EFL learning system. TESOL Journal, 7(3), 18-21.

[11] Daif-Allah, A. S. (2012). Beliefs about foreign language learning and their relationship to gender. English Language Teaching, 5(10), 20.-33.

[12] Fishbein, M., \& Ajzen, I. (1977). Belief, attitude, intention, and behavior: An introduction to theory and research. Reading, Mass: Addison-Wesley Pub. Co.

[13] Gerami, M. H., \& Baighlou, S. M. G. (2011). Language learning strategies used by successful and unsuccessful Iranian EFL students. Procedia-Social and Behavioral Sciences, 29, 1567-1576.

[14] Gregersen, T., \& Horwitz, E. K. (2002). Language learning and perfectionism: Anxious and non-anxious language learners' reactions to their own oral performance. The Modern Language Journal, 86(4), 562-570.

[15] Gu, P. Y. (2003). Vocabulary learning in a second language: Person, task, context and strategies. TESL-EJ, 7(2), 1-25.

[16] Horwitz, E. (2001). Language anxiety and achievement. Annual review of applied linguistics, 21, 112-126.

[17] Horwitz, E. K. (1987). Surveying student beliefs about language learning. Learner strategies in language learning, 3(5), 110129.

[18] Horwitz, E. K. (1988). The beliefs about language learning of beginning university foreign language students. The Modern Language Journal, 72(3), 283-294.

[19] Horwitz, E. K. (1999). Cultural and situational influences on foreign language learners' beliefs about language learning: A review of BALLI studies. System, 27(4), 557-576.

[20] Hosseini, S. B., \& Pourmandnia, D. (2013). Language Learners' Attitudes and Beliefs: Brief Review of The Related Literature and Frameworks. International Journal on New Trends in Education and Their Implications, 4(4), 63-74.

[21] Huwari, I., \& Al-Khasawneh, F. (2013). The reasons behind the weaknesses of writing in English among Pre-year students' at Taibah University. English for Specific Purposes World, 38(14), 1-9.

[22] Javid, C., \& Umer, M. (2014). Saudi EFL learners' writing problems: a move towards solution. Proceeding of the Global Summit on Education GSE, 4-5.

[23] Kayaoğlu, M. N. (2013). Poor And Good Learners' language Beliefs And Their Influence On Their Language Learning Strategy Use. Novitas-ROYAL (Research on Youth and Language), 7(1), 36-54.

[24] Malcolm, D. (2004). Investigating successful English learners in Arab medical schools. In Proceedings of the Independent Learning Conference 2003 (pp. 1-8).

[25] Mason, G. S., Shuman, T. R., \& Cook, K. E. (2013). Comparing the effectiveness of an inverted classroom to a traditional classroom in an upper-division engineering course. IEEE Transactions on Education, 56(4), 430-435.

[26] Nation, R., \& McLaughlin, B. (1986). Novices and experts: An information processing approach to the "good language learner" problem. Applied Psycholinguistics, 7(01), 41-55.

[27] Nespor, J. (1987). The role of beliefs in the practice of teaching. Journal of curriculum studies, 19(4), 317-328.

[28] Nunan, D. (2001). English as a global language. TESOL quarterly, 35(4), 605-606.

[29] Oxford, R. L. (2003). Language learning styles and strategies: Concepts and relationships. Iral, 41(4), 271-278.

[30] Park, H., \& Lee, A. R. (2005). L2 learners' anxiety, self-confidence and oral performance. In 10th Conference of Pan-Pacific Association of Applied Linguistics, Edinburgh University, conference proceedings (pp. 197-208).

[31] Peacock, M. (1999). Beliefs about language learning and their relationship to proficiency. International Journal of Applied Linguistics, 9(2), 247-263.

[32] Shoeib, A. (2004).The Effect of Vocabulary Strategy Training on Enhancing Overall English Proficiency. Al-Azhar University Library.

[33] Suwanarak, K. (2012). English language learning beliefs, learning strategies and achievement of Masters Students in Thailand. TESOL in Context $S, 3,1-15$.

[34] Yuen, C. O. (2002). Secondary students' English language learning beliefs and oral proficiency: a Hong Kong case study. $H K U$ Theses Online (HKUTO).

[35] Zoghi, M., Kazemi, S. A., \& Kalani, A. (2013). The effect of gender on language learning. Journal of Novel Applied Sciences, 2(4), 1124-1128.The Effect of Gender on Language Learning.

Muntaha Ali Mohammad Al Momani was born in Irbid city in Jordan on 16th of December 1979 she received her B.A in English for specific purposes from Jordan University for Science and Technology in 2001, and M.D in English teaching methods in Al-Hashimia University in 2005.

She is an instructor in Al-Balqa Applied University, Ajloun University College, department of English.

She taught obligatory courses as English (099), English (101), and English (102). Moreover, she taught skills like writing, reading, and speaking.

Her researches she starts focusing on the effect and using of Social media in the teaching methodologies.

Roba Mahmoud Ali AlOglah was born in Irbid city in Jordan on 14th of November 1982. she was Awarded here B.Sc. Degree In Information Technology by Al-Balqa' Applied University in the First Semester 2003/2004, and M.Sc. in Computer Information System by the Arab Academy for Banking And Financial Sciences in 2005.

She is currently an instructor at Al-Balqa' applied university, Ajloun University College, department of Applied Science. 
She taught many obligatory / selective courses for the undergraduates in the department as Computer Skills (1), Computer Skills (2), Visual Basic + Advance Visual Basic, C++, System Analysis, Database Management, Computer graphics, Computer security, Algorithms, Data structures, Computer networks, HTML, Software engineering., moreover she taught on-line many courses due to the COVID-19 pandemic .

Her research interest focusing on the following fields: Computer algorithms, Computer networks, Information retrieval, and recently due to the effect of the Pandemic; she starts researching on the effect and using of Social media in the teaching methodologies. 